\title{
HORDEUM VULGARE: A SUITABLE HOST FOR MASS PRODUCTION OF ARBUSCULAR MYCORRHIZAL FUNGI FROM NATURAL SOIL.
}

\author{
B. CHAURASIA* - P.K. KHARE \\ *e-mail: bhaskarchaurasia@rediffmail.com \\ EPB, GB Pant Institute of Himalayan Environment and Development, \\ Kosi-Katarmal, ALMORA (UA) 263463, India \\ *Corresponding author
}

(Received $12^{\text {th }}$ July 2004, accepted $4^{\text {th }}$ August 2005)

\begin{abstract}
Four plant species viz. Hordeum vulgare, Triticum aestivum, Phaseolus vulgaris and Phaseolus mungo were examined for mass production of consortium of AM fungi present in the rhizosphere soil. Rhizosphere soil were collected from teak dominated forest and was used as a source of AM inoculum. Surface sterilized seeds of all the four selected plant species were raised in a mixture of sterilized soil and sand in 3:1 ratio. Mass production of AM fungi was observed in terms of (\%) AM colonization, AM spore population, and effectiveness of AM consortia was recorded in terms of height and dry weight of inoculated and uninoculated plants. Out of four test species $\mathrm{H}$. vulgare responded as the most suitable host. After 60 days, $H$. vulgare showed the highest colonization (92\%) and 74 spores per 25 g soil. It was observed that plants having higher AM colonization showed higher AM spore production showing a positive correlation, however, it was not found in $T$. aestivum. Study indicates that $H$. vulgare is suitable for early colonization and mass production of AM fungi. After 90 days of pot culture, pot soil from all host were analyzed for AM flora. In all, eleven AM species were identified from the consortium. Maximum numbers of AM species (8 species) were found associated with $H$. vulgare. Three species of AM fungi i.e. Glomus aggregatum, G. fasciculatum and Sclerocystis pakistanica were found to dominate in the soil of $H$. vulgare.
\end{abstract}

Keywords. AM fungi, AM colonization, Glomus aggregatum, G. fasciculatum, Sclerocystis pakistanica, mass production

\section{Introduction}

Ubiquitous occurrence and importance of AM fungi for plant growth is now a wellestablished fact. Distribution and abundance of AM fungi vary greatly among different sites i.e. natural and manmade ecosystems [7,9]. Investigation on the distribution of AM fungi is still required to be taken up with particular reference to tropical forests. Natural soil offers consortium of indigenous mycorrhizal fungi and often used as source of inoculum. Since isolation and selection of AM species (effective for growth promotion) and raising of pure culture of these species is difficult, a suitable host is required to maintain the AM culture. The beneficial use of AM inoculum in agriculture and raising nurseries has been reported [15, 22].

Approximately 155 species of AM fungi have been described so far [13]. Some AM species are broadly effective while others, though they colonize many host species, may promote the growth of only a few $[6,23]$. Therefore, the first consideration in inoculum production is the choice of the fungal isolates which are capable of growth promotion of a 
given plant. Thus preliminary trails on a variety of isolates are required to find out the most effective ones. Another biological consideration in the production of inoculum is the host plant upon which the fungus will grow [17]. The degree of importance of this consideration also depends upon the growth system (pot culture, hydroponics, etc.). Mass propagation of AM fungi varies greatly on root structure, and habitat of host plant [5].

The objectives of present study were (i) selection of suitable host for mass production, and (ii) effectiveness of AM consortium present in the rhizosphere soil on selected host species, namely Triticum aestivum, Hordeum vulgare, Phaseolus vulgaris and P. mungo.

\section{Materials and methods}

\section{Study location and collection of soil samples}

The present study was carried in teak (Tectona grandis) dominated tropical drydeciduous forests around Sagar in Central India. Sagar district is situated a few kilometres north of Tropic of Cancer between $23^{\circ} 05^{\prime}-24^{\circ} 25^{\prime} \mathrm{N}$ and $78^{\circ} 10^{\prime}-79^{\circ} 15^{\prime} \mathrm{E}$ on an average altitude of $517 \mathrm{~m}$ above mean sea level. The soil samples were collected randomly after removing 5-10 $\mathrm{cm}$ of top layer, from teak dominated forest. Samples were thoroughly mixed and used, treated as inoculum.

\section{Selection of host}

Four-host plant species, viz. Triticum aestivum, Hordeum vulgare, Phaseolus vulgaris and $P$. mungo were tried for selection of the suitable host for mass production of AM spores. All the four species were selected on the basis of their (i) suitability to the agroclimatic conditions of the area; (ii) having thick root system for sizeable sporulation and colonization; and (iii) annual growth habit.

\section{Pot and potting mixture}

Open pot culture was used for the mass production of AM fungi. A layer of $100 \mathrm{~g}$ of collected soil samples (inoculum) was spread over pot mixture (sterilized sand : soil = $1: 3$; about $3 \mathrm{~kg}$ ) in earthen pots $(30 \mathrm{~cm}$ height and $25 \mathrm{~cm}$ diameter). These pots were used for the experimentation.

\section{Surface disinfection of seeds}

There will be enough number of microbes alongwith AM population in indigenous soil samples (inoculum) so there is no need of surface disinfection of seeds, but in order to decrease microbial contamination and to achieve healthy seedlings, seeds of Hordeum vulgare, Triticum aestivum, Phaseolus vulgaris and Phaseolus mungo were surface disinfected with $0.01 \%(\mathrm{w} / \mathrm{v}) \mathrm{HgCl}_{2}$ for 2 minutes and washed several (3-4) times with sterilized distilled water.

\section{Quantification of AM fungi}

Root samples and soil samples were collected at an interval of 15 days. AM colonization of root was examined after staining with $0.1 \%$ acid fuchsin [11]. Root segments, each approximately $1 \mathrm{~cm}$ long, were selected at random from a stained 
sample and mounted on microscopic slides in group of 10. Minimum 100 root segments were examined for each pot. Slide with stained root segments were carefully observed under microscope (Leica DML 30) under suitable magnifications. Per cent root colonization was calculated using following formula:

$$
\% \text { colonization }=\frac{\text { total number of colonized root pieces }}{\text { total number of root pieces examined }} \times 100
$$

\section{Effectiveness of AM fungi}

Effectiveness of consortium of AM fungi was determined by taking plant height and dry weight after 90 days of growth period.

\section{Isolation and identification of AM spores}

AM spores were determined per $25 \mathrm{~g}$ of soil. Spore isolation was done by wetsieving and decanting method [8]. Identification of AM fungal spores was done as per manual [20].

\section{Data analysis}

The criteria for statistical significance for per cent colonization was set at a table wide value at $P<0.05$ using LSD [21]. Standard deviation is reported in plant height and dry weight.

\section{Results}

As evident from the results, colonization was highest (92\%) in $H$. vulgare and minimum (62\%) in P. vulgaris after 60 days of inoculation (Table 1).

The results envisage that in $H$. vulgare colonization of AM fungi was highest in all the growth periods i.e., from 15 days to 60 days. Further, amongst the all host species the rate of colonization in $H$. vulgare was higher during later phase of growth period. Statistical analysis of the data for colonization showed significant differences when compared with initial and higher growth intervals (LSD-14.9 at $P<0.05$ ). On the whole, AM colonization in $H$. vulgare was significantly higher after 60 days than the other three host species. On the contrary minimum colonization occurred in P. vulgaris. Colonization by AM fungi appears to be lower in both the leguminous hosts ( $P$. vulgaris and $P$. mungo) as compared to the graminaceous host. Similar trends as the rate of colonization were observed during different period of growth.

Spore population was minimum ( 25 spores) in $P$. vulgaris and maximum (36 spores) in H. vulgare after 30 days (Fig. 1). H. vulgare appeared to be a host with higher AM spore production: 74 spores per $25 \mathrm{~g}$ soil and 92\% AM colonization after 60 days. It is interesting to note that the spore population was lower in T. aestivum (28 after 30 days and 57 after 60 days) though it has comparatively higher AM colonization. However, higher number spores were lower\% colonization was observed in P. mungo. In general it appears that the AM spore population followed the trend of colonization after 30 to 60 days of growth periods. A positive correlation was observed between root colonization and spore production in these species. (Table 1, Fig. 1). 
Table 1. Arbuscular mycorrhizal colonization (\%) in four hosts plant used for mass production of AM fungi

\begin{tabular}{l|cccc}
\hline \multicolumn{1}{c|}{ host plant } & \multicolumn{4}{c}{ period (days) } \\
\\
\hline H. vulgare & $\mathbf{1 5}$ & $\mathbf{3 0}$ & $\mathbf{4 5}$ & $\mathbf{6 0}$ \\
T. aestivum & $54^{\mathrm{cde}}$ & $60^{\mathrm{def}}$ & $72^{\mathrm{f}}$ & $92^{\mathrm{g}}$ \\
P. vulgaris & $40^{\mathrm{abc}}$ & $49^{\mathrm{abcd}}$ & $59^{\mathrm{def}}$ & $71^{\mathrm{f}}$ \\
P. mungo & $37^{\mathrm{a}}$ & $44^{\mathrm{abc}}$ & $50^{\mathrm{abcd}}$ & $62^{\mathrm{def}}$ \\
& $38^{\mathrm{ab}}$ & $41^{\mathrm{abc}}$ & $52^{\mathrm{bcde}}$ & $66^{\mathrm{ef}}$ \\
\hline
\end{tabular}

Values with different alphabets are significantly different at $P<0.05$

Results of growth performance of host after inoculum of consortium of AM fungi clearly indicated that AM inoculation increased the height of host plants compared to uninoculated plants. Dry weights of inoculated host plants were also found increased in all the host species (Table 2).

Dry weight of host was higher in inoculated plants of $H$. vulgare $(1.44 \mathrm{~g}$ per plant) than in the uninoculated plants $(1.10 \mathrm{~g}$ per plant). However it was $1.40 \mathrm{~g}$ per plant in inoculated and $0.93 \mathrm{~g}$ per plant in uninoculated plant of $T$. aestivum. Comparatively a little increase in dry weight was recorded in inoculated plant of $P$. mungo and $P$. vulgaris $(8-9 \%)$.

Maximum increase in height was observed in inoculated leguminous plants, i.e. $P$. vulgaris and $P$. mungo (41\%) as compared to uninoculated. However, this increase in height was comparatively of lower magnitude in graminaceous plant, i.e. H. vulgare (24\%) and T. aestivum (14\%). A very interesting trend was observed with dry weight of host plants, where the increase in inoculated plants was more in $H$. vulgare $(30.90 \%)$ and T. aestivum (50.53\%) as compared to P. vulgaris $(9.18 \%)$ and $P$. mungo $(8.00 \%)$ (Table 2). It appears that as far as the productivity of the host plant is concerned, the maximum effect of AM inoculation occurred in graminaceous than in the legumes.

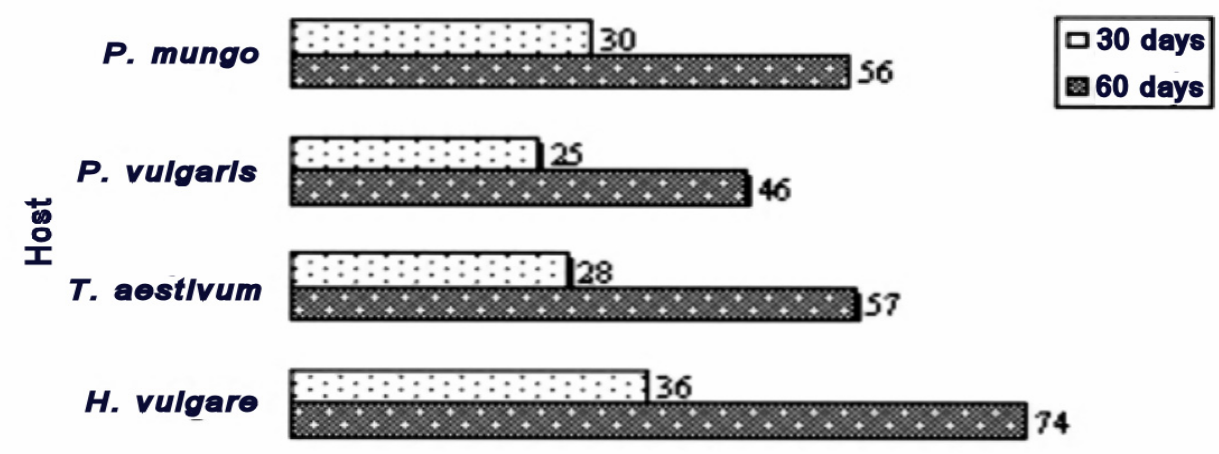

Number of spore per $25 \mathrm{~g}$ soil

Figure 1. Spore population of AM fungi per $25 \mathrm{~g}$ soil from four host used for mass production 
After 90 days, AM spores were isolated from the pots. In all, eleven different species of AM fungi were identified from the rhizosphere soil of inoculated plants (Table 3, Fig. 2). Maximum numbers of AM species were found associated with rhizosphere soil of $H$. vulgare in comparison of other host plants. Six of these species belong to genus Glomus namely Glomus aggregatum Schenck \& Smith emend. Koske, G. ambisporum Smith \& Schenek, G. fasciculatum (Thaxter) Gerdemann \& Trappe emend. Walker \& Koske, G. heterosporum Smith \& Schenck, G. mosseae (Nicolson \& Gerdemann) Gerdemann \& Trappe, G. microaggregatum Koske, Gemma \& Olexia. Three species of AM fungi, i.e. Glomus aggregatum, G. fasciculatum and Sclerocystis pakistanica were found dominated in the rhizosphere soil of $H$. vulgare in comparison to rest of host species (Table 3).

Table 2: Height and dry weight of control (C) and AM inoculated (In) plant after 90 days

\begin{tabular}{l|ccc|ccc}
\hline \multirow{2}{*}{ host plant } & \multicolumn{2}{|c|}{ height (cm ) } & \% increase & \multicolumn{2}{c}{ plant dry weight (g) } & \% increase \\
& $\mathrm{C}$ & $\mathrm{In}$ & over control & $\mathrm{C}$ & In & over control \\
\hline H. vulgare & $33.00 \pm 1.94$ & $41.00 \pm 1.78$ & 24.24 & $1.10 \pm 0.30$ & $1.44 \pm 0.36$ & 30.90 \\
T. aestivum & $32.00 \pm 1.85$ & $36.50 \pm 1.14$ & 14.06 & $0.93 \pm 0.17$ & $1.40 \pm 0.14$ & 50.53 \\
P. vulgaris & $21.00 \pm 1.53$ & $29.75 \pm 1.48$ & 41.66 & $0.98 \pm 0.21$ & $1.07 \pm 0.18$ & 9.18 \\
P. mungo & $23.00 \pm 0.63$ & $32.50 \pm 1.87$ & 41.33 & $1.00 \pm 0.2$ & $1.08 \pm 0.32$ & 8.00 \\
\hline
\end{tabular}

Values are mean of six replicates $\pm S D$

\section{Discussion}

AM fungal colonization and subsequent spore formation and production depends upon the type of host as well as the duration of infection of these symbiotic organisms. Generally, with increase in the growth period after infection, root colonization of host increase. However, this increase in colonization and period do not have greater bearing on spore production. It is the host type, which is more important for spore production. Therefore, the relationship between colonization and rate of colonization with growth period do not vary greatly in different hosts. Positive effect of AM colonization on increasing AM population were found in $H$. vulgare and $P$. mungo. Al-Raddad [3] also found highest spore population with cereals plant followed by chickpea and beans. However, this relationship does not exist in $T$. aestivum and $P$. vulgaris where with higher root colonization, the number of spores were not high. The present results are in accordance with earlier findings where no correlation could be established between spore number and root colonization [4].

Results of the experiments for mass production of AM inoculum with four selected host plants indicate a gradual increase in root colonization and spore number with the period of growth and increase in the size of plant.

This trend was more evident in H. vulgare in comparison to other hosts. Among the different hosts, $H$. vulgare and $T$. aestivum had a larger root system as they belong to graminaceous crop. Therefore, it seems that monocots with rapidly developing fibrous root system can be considered as ideal trap plants for producing AM spores. Higher inoculum densities were often found associated with higher root colonization in the early growing season in $H$. vulgare and T. aestivum. Larger plant size has been associated with

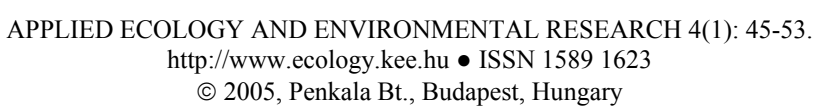




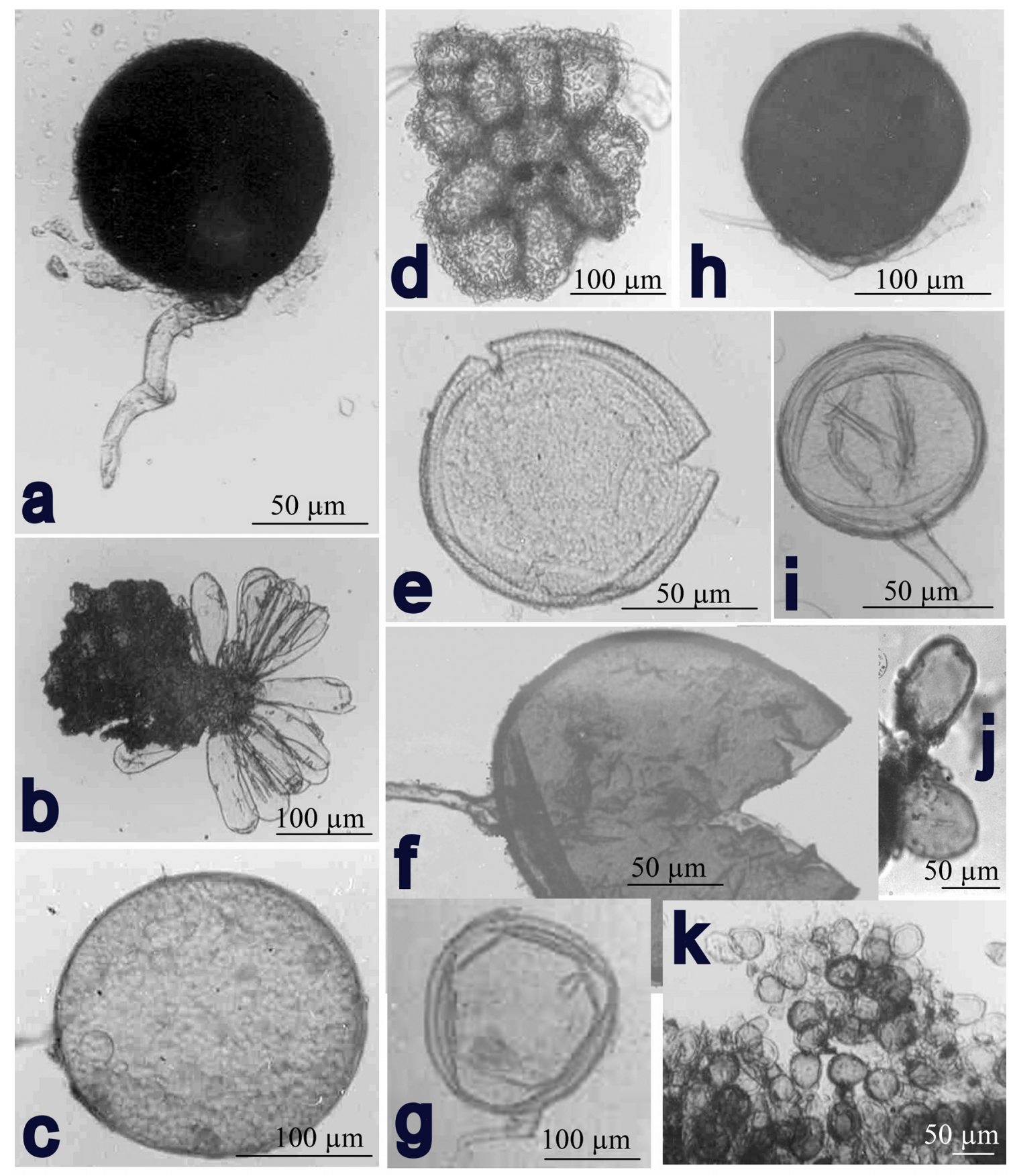

Figure 2. Identified arbuscular mycorrhizal fungal (AMF) species. (a) Glomus ambisporum; (b) a part of sporocarp with peridium of Sclerocystis pakistanica; (c) Acaulospora sp.; (d) sporocarp of Sclerocystis sinuosa; (e) Acaulospora scrobiculata; (f) Gigaspora sp.; (g) Glomus mosseae; (h) Glomus heterosporum; (i) Glomus fasciculatum; (j) Glomus aggregatum; (k) Glomus microaggregatum. 


\begin{tabular}{|c|c|c|c|c|c|}
\hline & Name of AM species & 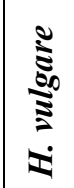 & 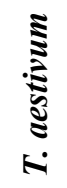 & 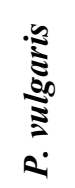 & 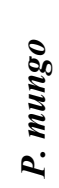 \\
\hline 1 & Acaulospora scrobiculata & ++ & - & - & - \\
\hline 2 & Acaulospora sp. & - & + & - & - \\
\hline 3 & Glomus aggregatum Schenck \& Smith emend. Koske & ++ & + & + & + \\
\hline 4 & Glomus ambisporum Smith \& Schenek & + & ++ & - & - \\
\hline 5 & Glomus fasciculatum (Thaxter) Gerdemann \& Trappe emend. Walker \& Koske & +++ & + & + & + \\
\hline 6 & Glomus heterosporum Smith \& Schenck & + & - & + & + \\
\hline 7 & Glomus mosseae (Nicolson \& Gerdemann) Gerdemann \& Trappe & + & - & + & + \\
\hline 8 & Glomus microaggregatum Koske, Gemma \& Olexia & - & + & - & - \\
\hline 9 & Sclerocystis pakistanica Iqbal \& Bushra & +++ & ++ & ++ & + \\
\hline 10 & Sclerocystis sinuosa Gerdemann \& Bakshi & - & + & - & + \\
\hline 11 & Gigaspora sp. & - & - & + & - \\
\hline
\end{tabular}

increased levels of sporulation, probably because larger plant often have more extensive root system than smaller plants, allowing greater mycorrhizal colonization and sporulation [18].

It is also evident from the data that AM association has further contributed to the growth of all inoculated host plant. This increase in growth on account of AM inoculation is now a well-established fact and in a number of studies from different parts of the world on different plants, such conclusions have been drawn [2].

In the present investigation the high percentage of root colonization and spore population resulted in increased height and dry weight of both graminaceous host in comparison to leguminous host. It has been observed that higher root colonization at the time of sampling may be attributed to high number of secondary roots, and its density, which favour active mycorrhizal colonization $[14,19]$. Similar results were obtained by [12]. Rangeley et al. [16] have also reported that colonization of root is directly proportional to root growth.

The intensive root colonization of host resulted in the better plant growth in term of dry matter. These results are in line with that of Abbott and Robson [1]. It was also observed that colonization and spore population vary with time and increases with advancing growth stages of the plant [10]. As evident from the results in the pot experiments, rapid AM colonization and higher spores production was observed in $H$. vulgare. In this experiment maximum effectiveness of AMF species was also observed in $H$. vulgare. Therefore, soil of $H$. vulgare can be used as inoculum and this host can be used for mass propagation of pure cultures of AMF. Results also envisaged that either host plants favour the association of particular AM species or AM fungi may show some preference for the host.

Acknowledgements. The authors are thankful to Dr. V.S. Mehrotra for his help for identification in AM fungi and also thank Dr. Anita Pandey for her critical suggestions. 


\section{REFERENCES}

[1] Abbott, L.K. \& Robson, A.D. (1984): The effect of mycorrhizae on plant growth. - In: Powell, C.L. \& Bagyaraj, D.J. (eds): Mycorrhiza. CRC Press, Boca Raton, Florida, pp. $113-130$.

[2] Abbott, L.K. \& Robson, A.D. (1982): The role of vesicular-arbuscular-mycorrhizal fungi in agriculture and the selection of fungi for inoculation. - Australian Journal of Agricultural Research 33: 389-408.

[3] Al-Raddad, A. (1995): Mass production of Glomus mosseae spores. - Mycorrhiza 5: 229-231.

[4] Al-Raddad, A. (1991): Response of bean, broad bean and chickpea plants to inoculation with Glomus species. - Scientia Horticulturae 146: 195-200.

[5] Bever, J.D, Morton, J.B., Antonovics, J. \& Schultz, P.A. (1996): Host-dependent sporulation and species diversity of arbuscular mycorrhizal fungi in mown grassland. - Journal of Ecology 84: 71-82.

[6] Bever, J.D. (2002): Host specificity of AM fungal population growth rates can generate feedback on plant growth. - Plant and Soil 244: 281-290.

[7] Chaurasia, B. (2001): Ecological study of tropical forest trees with special reference to vesicular arbuscular mycorrhizal (VAM) association. Ph.D. Thesis, Dr. H.S. Gour University, Sagar, M.P. India, 172 pp.

[8] Gerdemann, J.W. \& Nicolson, T.H. (1963): Spores of mycorrhizal endogone species extracted from soil by wet sieving and decanting. - Transaction of British Mycological Society: $235-244$.

[9] Gianinazzi-Pearson, V., Gianinazzi, S. \& Trouvelot, A. (1985): Evaluation of the infectivity and the effectiveness of indigenous vesicular-arbuscular fungal populations in some agricultural soils in Burgundy. - Canadian Journal of Botany 63: 1521-1524.

[10] Johri, B.N. \& Methew, J. (1989): Strategies for mass cultivation of vesicular arbuscular mycorrhizal fungi. In: Bilgrami, K.S. (ed.): Plant microbe interactions. Narendra Publication House, Delhi, pp. 293-303.

[11] Kormanik, P.P., Bryan, W.C. \& Schultz, R.C. (1980): Procedure and equipment for staining large number of plant roots for endomycorrhizal assay. - Canadian Journal of Microbiology 26: 536-538.

[12] Lawley, R.A., Newmann, E.I. \& Campbell, R. (1982): Abundance of endomycorrhizas and root surface microorganisms on three grasses grown separately and in mixture. - Soil Biology and Biochemistry 14: 237-240.

[13] Morton, J.B. \& Bentivenga, S.P. (1994): Levels of diversity in endomycorrhizal fungi (Glomales, Zygomycetes) and their role in defining taxonomic and non-taxonomic groups. - Plant and Soil 159: 47-59.

[14] Mosse, B., Powell, C.L. \& Haymann, D.S. (1976): Plant growth responses to vesiculararbuscular mycorrhiza. IV Intractions between VA mycorrhiza rock phosphate and symbiotic nitrogen fixation. - New Phytologist 76: 331-342.

[15] Muthukumar, T., Ydaiyan, K. \& Rajeshkannan, V. (2001): Response of neem (Azadirachta indica A. Juss) to indigenous arbuscular mycorrhizal fungi, phosphate-solubilizing and asymbiotic nitrogen-fixing bacteria under tropical nursery conditions. - Biology and Fertility of Soils 34: 417-426.

[16] Rangeley, A., Daft, M.J. \& Newbould, P. (1982): The inoculation of white clover with mycorrhizal fungi in unsterile hill soils. - New Phytologist 92: 89-102.

[17] Ryan, M.H. \& Graham, J.H. (2002): Is there a role for arbuscular mycorrhizal fungi in production agriculture? - Plant and Soil 244: 263-271. 
[18] Saif, S. \& Khan, A. (1977): The effect of vesicular-arbuscular mycorrhizal associations on growth of cereals 3. Effects on barley growth. - Plant and Soil 47: 17-26.

[19] Sanders, F.E., Tinker, P.B., Black, R.L.B. \& Palmerley, S.M. (1977): The development of endomycorrhizal root system. I. Spread of infection and growth promoting effects with four species of vesicular endophyte. - New Phytologist 78: 257-268.

[20] Schenck, N.C. \& Perez, Y. (1990): A manual for identification of vesicular-arbuscular mycorrhizal fungi. INAM University of Florida, Gainesville, FL. 286 pp.

[21] Snedecor, G.W. \& Cochran, W.G. (1967): Statistical Methods. The Iowa State University Press, U.S.A.

[22] Smith, S.E. \& Read, D.J. (1997): Mycorrhizal Symbiosis. Academic Press, San Diego, CA, 605 pp.

[23] Sylvia, D.M., Wilson, D.O., Graham, J.H., Maddox, J.J., Miller, P., Morton, J.B., Skipper, H.D., Wright, S.F. \& Jarstfer, A.G. (1993): Evaluation of vesicular-arbuscular mycorrhizal fungi in diverse plants and soils. - Soil Biology and Biochemistry 25: 705-713. 